\title{
POSTUPAK SERTIFIKACIJE BESPILOTNIH VAZDUHOPLOVA
}

\author{
Aleksandar Đurić1, \\ Dragan Vasiljević1, \\ Miroslav Jovanović ${ }^{1}$ \\ Dalibor Kutnjak', \\ Julijana Vasiljević ${ }^{2}$
}

\section{${ }^{1}$ Ministarstvo odbrane ${ }^{2}$ Ministarstvo prosvete}

Correspondence:

Aleksandar Đurić

e-mail:

aleksandar_djrc@yahoo.com
Rezime:

Tema rada je postupak sertifikacije bespilotnih vazduhoplova, sa posebnim osvrtom na Republiku Srbiju.

Sa razvojem tehnologije, bespilotni vazduhoplovi postaju sve dostupniji širokoj javnosti. Zato je neophodno pristupiti njihovoj sertifikaciji kako bi se omogućio bezbedan rad rukovalaca bespilotnoh vazduhoplova, ali i ostalih lica koja mogu biti ugrožena upotrebom. Ova oblast je, kao i sama upotreba bespilotnih vazduhoplova u Republici Srbiji, još uvek u razvoju i ima mogućnosti za znatna unapređenja.

Ključne reči:

bespilotni vazduhoplovi, operater, sertifikacija, pravilnik o bespilotnim vazduhoplovima.

\section{UVOD}

Bespilotni vazduhoplov je vrsta vazduhoplova čiji je let kontrolisan od strane računara koji se nalazi na vazduhoplovu, ili čijim letom se daljinski upravlja od strane operatera na zemlji [1]. Operater na zemlji je lice koje neposredno upravlja bespilotnim vazduhoplovom, kontroliše njegov let, programira sistem upravljanja bespilotnim vazduhoplovom i koje je odgovorno za njegov let. Nije dozvoljeno korišćenje bespilotnih vazduhoplova čiji je let u potpunosti kontrolisan od strane računara koji se nalazi na njemu.

Bespilotni vazduhoplovi konstruisani su za višekratnu upotrebu i definišu se po pravilima struke kao i ostali vazduhoplovi, ali bez posade i pilota. Iako se konstruišu za višekratnu upotrebu, mogu biti i sa jednokratnom upotrebom, kao na primer „samoubice”, kada imaju maksimalno pojednostavljenu konstrukciju.

Klasifikacija bespilotnih vazduhoplova može biti izvršena na osnovu više aspekata i činilaca.

Prema načinu upravljanja, bespilotni vazduhoplovi dele se na:

- Neupravljane bespilotne vazduhoplove;

- Automatski upravljane bespilotne vazduhoplove;

- Daljinski upravljane bespilotne vazduhoplove, kojima upravlja pilot smešten u stanici ili kabini na vozilu. 
Evropska asocijacija (European Association of Unmanned Vehicles Systems - EUROUVS) sačinila je klasifikaciju bespilotnih vazduhoplova na osnovu nekoliko parametara kao što su visina leta, autonomija, brzina, maksimalna težina u poletanju, veličina itd.

Prema povezanim parametrima mase, vremena doleta i nadmorskoj visini leta, bespilotni vazduhoplovi dele se na:

- „mikro” bespilotne vazduhoplove - sa masom do $10 \mathrm{~kg}$, autonomijom (trajanjem) leta oko $1 \mathrm{~h} \mathrm{i}$ radijusom kretanja do $1 \mathrm{~km}$;

- „mini” bespilotne vazduhoplove - sa masom do $50 \mathrm{~kg}$, autonomijom leta od nekoliko časova i radijusom od $3 \mathrm{~km}$ do $5 \mathrm{~km}$;

- „midi” bespilotne vazduhoplove - sa masom do $1000 \mathrm{~kg}$, autonomijom leta od $10 \mathrm{~h}$ do $12 \mathrm{~h} \mathrm{i}$ visinom leta od $9 \mathrm{~km}$ do $10 \mathrm{~km}$;

- „teške” bespilotne letelice - na visinama do 20 $\mathrm{km}$ leta i autonomijom leta duže od $24 \mathrm{~h}$.

Bespilotni vazduhoplovi su u početku bili ograničeni samo na vojnu upotrebu u različitim programima, ali su se sa razvojem tehnologije počeli u većoj meri koristiti u civilnoj upotrebi.

Broj bespilotnih vazduhoplova koji se koriste u civilnim strukturama povećava se svakodnevno u različitim strukturama, od obične upotrebe iz zadovoljstva, pa sve do specijalizovane upotrebe u raznim sferama poljoprivrede, industrije, borbe protiv elementarnih nepogoda, hemijsko-bioloških akcidenata i slično.

Integracija bespilotnih vazduhoplova u nacionalni vazdušni prostor predstavlja sledeći veliki korak u evoluciji civilnog vazduhoplovstva [2].

Upotreba bespilotnih vazduhoplova u Republici Srbiji regulisana je Pravilnikom o bespilotnim vazduhoplovima (u daljem tekstu Pravilnik), pri čemu se odredbe ovog Pravilnika ne primenjuju na bespilotne vazduhoplove koji se projektuju, proizvode i koriste za operativne potrebe organa nadležnih za poslove odbrane, unutrašnjih poslova $\mathrm{i}$ carine, kao ni na letenje bespilotnih vazduhoplova $\mathrm{u}$ zatvorenom prostoru [3].

Pravilnik daje nekoliko klasifikacija bespilotnih vazduhoplova.

Prema nameni, bespilotni vazduhoplovi dele se na:

- Bespilotne vazduhoplove koji se koriste u privredne svrhe;

- Bespilotne vazduhoplove koji se koriste u neprivredne svrhe (vazduhoplovni modeli i bespilotni vazduhoplovi koji se koriste u naučne, obrazovne i druge svrhe).
Prema operativnoj masi i performansama bespilotni vazduhoplovi razvrstavaju se na sledeće kategorije:

- Kategorija 1 - obuhvata bespilotne vazduhoplove čija je operativna masa manja od $0,5 \mathrm{~kg}$, sa maksimalnom visinom leta do $50 \mathrm{~m}$, maksimalnom brzinom leta do $30 \mathrm{~m} / \mathrm{s}$ i maksimalnim doletom do $100 \mathrm{~m}$;

- Kategorija 2 - obuhvata bespilotne vazduhoplove čija je operativna masa od $0,5 \mathrm{~kg}$ do $5 \mathrm{~kg}$, sa maksimalnom visinom leta do $150 \mathrm{~m}$, maksimalnom brzinom leta do $30 \mathrm{~m} / \mathrm{s}$ i maksimalnim doletom do $2500 \mathrm{~m}$;

- Kategorija 3 - obuhvata bespilotne vazduhoplove čija je operativna masa od $5 \mathrm{~kg}$ do $20 \mathrm{~kg}$, sa maksimalnom visinom leta do $500 \mathrm{~m}$, maksimalnom brzinom leta do $55 \mathrm{~m} / \mathrm{s}$ i maksimalnim doletom do $2500 \mathrm{~m}$;

- Kategorija 4 - obuhvata bespilotne vazduhoplove čija je operativna masa od $20 \mathrm{~kg}$ do $150 \mathrm{~kg}$, bez ograničenja visine, brzine leta i doleta [3].

\section{POSTOJEĆA REGULATIVAZA SERTIFIKACIJU BESPILOTNIH VAZDUHOPLOVA}

Postupak i elementi sertifikacije definisani su u Pravilniku.

Pravilnikom se propisuju uslovi za bezbedno korišćenje bespilotnih vazduhoplova, njihovo razvrstavanje, evidentiranje, održavanje, kao i uslovi koje moraju da ispune lica koja koriste bespilotne vazduhoplove. Pravilnik se ne primenjuje na bespilotne vazduhoplove čija je operativna masa manja od $0,5 \mathrm{~kg}$, ako njihova maskimalna brzina ne prelazi $20 \mathrm{~m} / \mathrm{s}$ i koji dostižu maksimalni dolet do 15 $\mathrm{m}$ i maksimalnu visinu do $10 \mathrm{~m}$.

Pravilnik definiše da se bespilotni vazduhoplovi koji se koriste u privredne svrhe, kao i bespilotni vazduhoplovi kategorija 2, 3 i 4 koji se koriste u neprivredne svrhe, upisuju u Evidenciju bespilotnih vazduhoplova koju vodi Direktorat civilnog vazduhoplovstva Republike Srbije (u daljem tekstu Direktorat) i obeležavaju se evidencionom oznakom. Upis u evidenciju bespilotnih vazduhoplova vrši se na zahtev vlasnika ili operatera bespilotnog vazduhoplova, po ovlašćenju vlasnika bespilotnog vazduhoplova, pri čemu se uz zahtev podnosi uputstvo proizvođača za korišćenje i održavanje bespilotnog vazduhoplova. Prema Pravilniku, operater je dužan da obezbedi da se bespilotni vazduhoplov održava u skladu sa uputstvima proizvođača. 
Definisano je da se let bespilotnih vazduhoplova može realizovati samo u alociranom delu vazdušnog prostora (delu vazdušnog prostora koji je utvrdio pružalac usloga kontrole letenja, u kojem se odvija let bespilotnog vazduhoplova), a operater u definisanom roku traži alociranje vazdušnog prostora na definisanom obrascu, sa odobrenjem Direktorata za svaki let, najkasnije pet radnih dana pre nameravanog leta bespilotnog vazduhoplova.

Operater bespilotnog vazduhoplova može da koristi bespilotni vazduhoplov u privredne svrhe ako Direktorat prihvati njegovu izjavu o osposobljenosti za obavljanje planiranih aktivnosti. Izjava o osposobljenosti sadrži:

- Ime/naziv i adresu/sedište operatera;

- Opis planiranih aktivnosti;

- Evidencionu oznaku bespilotnog vazduhoplova;

- Podatke o licu koje upravlja bespilotnim vazduhoplovom;

- Navod da je upoznat sa odredbama Pravilnika i da će bespilotni vazduhoplov koristiti u skladu sa njim.

Zahtev za alokaciju vazdušnog prostora može se podneti pisanim putem, poštom, faksom i elektronskom poštom. O zahtevu, na osnovu raspoloživosti zahtevanog dela vazdušnog prostora, odlučuje jedinica za civilnovojnu koordinaciju. Veoma je bitno napomenuti da se na zahtev Ministarstva odbrane i Ministarstva unutrašnjih poslova, u slučaju potrebe realizovanja letova posebne namene u delu vazdušnog prostora koji je alociran za let bespilotnog vazduhoplova, jedinica za civilno-vojnu koordinaciju stavlja van snage odluku o alokaciji vazdušnog prostora o čemu odmah obaveštava operatera bespilotnog vazduhoplova.

Pravilnikom su definisane i određene zone u kojima nije dozvoljeno letenje bespilotnog vazduhoplova:

- U zoni do $5 \mathrm{~km}$ od referentne tačke aerodroma koji se nalazi u klasi D (osim po ododbrenju Direktorata);

- Letenje noću i van vidnog polja operatera bespilotnog vazduhoplova;

- Maksimalno dozvoljena visina lite $100 \mathrm{~m}$ iznad tla, osim po posebnom odobrenju Direktorata;

- Maksimalno dozvoljena horizontalna udaljenost bespilotnog vazduhoplova od operatera $500 \mathrm{~m}$ itd.

Lice koje upravlja bespilotnim vazduhoplovom mora biti punoletno i zdravstveno sposobno, što dokazuje lekarskim uverenjem u skladu sa uverenjima za određene kategorije motornih vozila ili vozačkom dozvolom izdatom u skladu sa Zakonom o bezbednosti u saobraćaju na putevima, izuzev dozvola izdatih za kategorije M i F.
Lice koje upravlja bespilotnim vazduhoplovima mora imati potvrdu o položenoj proveri znanja izdatoj od strane Direktorata na neograničeno vreme.

\section{PREDLOG METODE}

Sertifikacija u oblasti bespilotnih vazduhoplova načelno se može podeliti na dve oblasti:

1. Sertifikacija operatera bespilotnog vazduhoplova;

2. Sertifikacija bespilotnog vazduhoplova.

Sertifikaciju operatera u skladu sa važećim Pravilnikom o bespilotnim vazduhoplovima vrši Direktorat. Nakon položene provere znanja i dostavljanja definisane dokumentacije, operater dobija potvrdu na neograničeno vreme o poznavanju vazduhoplovnih propisa. Međutim, s obzirom na dinamične promene u oblasti bespilotnih vazduhoplova, iskustva mnogih zemalja govore da se potvrde izdaju na ograničeni vremenski period, nakon čega se vrši resertifikacija operatera. Ova odrednica je mnogo prihvatljivija jer zahteva od operatera da prati promene vazduhoplovnih propisa i da stalno obnavlja dostignuta znanja u ovoj oblasti, da bude stalno upoznat sa uputstvom za rad i uputstvom za održavanje bespilotnog vazduhoplova.

Sertifikacija bespilotnih vazduhoplova je oblast koja je malo obuhvaćena postojećim regulativama i Pravilnikom. Bespilotni vazduhoplovi se u skladu sa Pravilnikom koriste u sledećim reonima:

- Rejon I - neizgrađeno ili nenaseljeno područje u kome nema ljudi, osim lica koje upravlja bespilotnim vazduhoplovom;

- Rejon II - izgrađeno ali nenaseljeno područje u kome postoje građevinski objekti koji nisu namenjeni za život ljudi, u kome je moguće povremeno kraće zadržavanje ljudi;

- Rejon III - naseljeno područje, u kome postoje građevinski objekti namenjeni za stalni život i boravak ljudi;

- Rejon IV - gusto naseljeno područje, urbane ili centralne gradske zone, kao i svih područja na kojima se okuplja veliki broj ljudi.

Iz navedenog se može videti da se letenje bespilotnih vazduhoplova može realizovati, kako u nenaseljenim, tako i naseljenim područjima. Naročito je važan aspekt korišćenja bespilotnih vazduhoplova u gusto naseljenim područjima, gde problemi u radu mogu dovesti i do povređivanja drugih lica. 
Shodno tome, neophodno bi bilo razmotriti i uređenje oblasti tehničke sertifikacije bespilotnih vazduhoplova.

Pre same sertifikacije, neophodno je definisati telo koje će vršiti sertifikaciju i davati validne sertifikate. Ovu oblast mogu vršiti ovlšćene laboratorije ili druge ustanove sa definisanim minimumom stručnog kadra koja ispunjava uslove za stručni pregled tehničke dokumentacije bespilotnog vazduhoplova i može da realizuje postupak ispitivanja, merenja i sertifikacije bespilotnog vazduhoplova.

Nakon definisanja ovlašćenog tela za vršenje sertifikacije, neophodno je definisati metod sertifikacije.

U načelu, sertifikacija bespilotnih vazduhoplova sadrži nekoliko delova:

- Pregled tehničke dokumentacije bespilotnog vazduhoplova - ovaj pregleda sadrži pregled i proučavanje obavezne dokumentacije koju svaki bespilotni vazduhoplov mora imati. U ovom delu vrši se pregled uputstva za rukovanje bespilotnim vazduhoplovom, uputstva za održavanje bespilotnog vazduhoplova i pregled prethodno izdatog sertifikata za bespilotni vazduhoplov (ako je operater, odnosno vlasnik bespilotnog vazduhoplova, ranije vršio sertifikaciju);

- Pregled izveštaja ovlašćene laboratorije o proveri tehničkih karakteristika bespilotnog vazduhoplova - realizuje se pregled izveštaja druge ovlašćene laboratorije o ispitivanju tehničkih karakteristika vazduhoplova tehničkih karakteristika datih u uputstvu za rad ili održavanje bespilotnog vazduhoplova;

- Provera tehničkih karakteristika bespilotnog vazduhoplova - provera pojedinih karakteristika bespilotnih vazduhoplova iz uputstva za rukovanje i održavanje bespilotnog vazduhoplova u laboratorijskim uslovima. U okviru ovoga, vršila bi se provera komponenti bespilotnih vazduhoplova od pogonskog elementa, modula za komandovanje, osnovne konstrukcije itd. prema nacionalnim vazduhoplovnim standardima za pojedine elemente i delove bespilotnih vazduhoplova. Ukoliko nema definisanih nacionalnih standarda, pregled se realizuje prema internacionalnim standardima vezanim za bespilotne vazduhoplove, odnosno vazduhoplove uopšte;

- Provera rada i funkcionalnosti bespilotnog vazduhoplova - praktična provera rada bespilotnog vazduhoplova na zemlji i letenjem sa elementima letenja koje uputstvo za rad bespilotnog vazduhoplova predviđa i odobrava;
- Provera bespilotnog vazduhoplova sa aspekta bezbednosti u rukovanju i radu - vrši se provera elemenata i bespilotnih vazduhoplova u celosti sa aspekta bezbednog rada u letu, proveri funkcionisanja bezbednosnih protokola bespilotnog vazduhoplova (ako ih bespilotni vazduhoplov poseduje), kao na primer provera rada bespilotnog vazduhoplova nakon gubljenja veze sa operaterom, provera protokola o prinudnom prizemljenju ili povratku u tačku poletanja kada dođe do gubitka veze sa operaterom i slično, provera sa aspekta elektromagnetne komatibilnosti i imunosti sistema bespilotnog vazduhoplova itd.

Postupak sertifikacije dozvoljava priznavanje sličnog sertifikata i izveštaja izdatog od strane druge ovlašćene laboratorije, što je naročito bitno za bespilotne vazduhoplove koji se proizvode i kupuju u inostranstvu.

Tehničkom sertifikacijom bespilotnih vazduhoplova uz definisanu sertifikaciju operatera bespilotnog vazduhoplova zaokružila bi se oblast upotrebe i korišćenja bespilotnih vazduhoplova u komercijalne svrhe. Ovo je naročito bitno jer greške u radu bespilotnih vazduhoplova, nastale usled neznanja operatera ili usled tehničkih problema u radu bespilotnog vazduhoplova, mogu imati ozbiljne poslodice na lica u gusto naseljenim područjima iznad kojih bespilotni vazduhoplovi lete, ali i na druge objekte koji koriste vazdušni prostor.

\section{ZAKLJUČAK}

Sertifikacija bespilotnih vazduhoplova sastoji se od:

- Sertifikacije operatera bespilotnog vazduhoplova - koja je trenutno definisana u Pravilniku;

- Sertifikacije bespilotnog vazduhoplova - koja je trenutno malo definisana oblast.

S obzirom na to da se bespilotni vazduhoplovi mogu koristiti u nenaseljenim, ali i gusto naseljenim područjima, potrebno je izvršiti sertifikaciju samih bespilotnih vazduhoplova, sa posebnim akcentom na bezbednost u radu i sprečavanje mogućih posledica usled otkaza u letu.

Postupak sertifikacije bespilotnih vazduhoplova definisao bi metod pregleda dokumentacije i samog bespilotnog vazduhoplova, laboratorijska merenja i provere sa aspekta bezbednosti leta i korišćenja. Na ovaj način definisali bi se i zahtevi koje bespilotni vazduhoplovi koriste u civilne svrhe u zemlji moraju ispunjavati, čime bi se uticalo na njihov uvoz i izradu i sprečilo komercijalno korišćenje nebezbednih i nesertifikovanih uređaja. 
Krajnji cilj je povećanje bezbednosti ljudi u zemlji koji se nalaze u zoni letenja bespilotnih vazduhoplova, izrada/uvoz kvalitetnih bespilotnih vazduhoplova i razvoj sistema bezbednosti letenja bespilotnih vazduhoplova u zemlji.

\section{LITERATURA}

[1] Zakon o vazdušno saobraćaju (“Službeni glasnik Republike Srbije” broj 73/10, 57/11, 93/12, 45/15 i 66/15-drugi zakon).

[2] Kelly J. Hayhurst, Jeffrey M. Maddalon, Paul S. Miner, George N. Szatkowski „Preliminary considerations for classifying hazards of unmanned aircraft sistems", Langley research center, Hampton, Virginia, NASA, 2007.

[3] “Službeni glasnik Republike Srbije” broj 108/15. 